\title{
Susceptibilidad bacteriana a antimicrobianos. Especies aisladas en pacientes ambulatorios de la Región Metropolitana, Chile, año 2007
}

\author{
Rossanna Camponovo C.
}

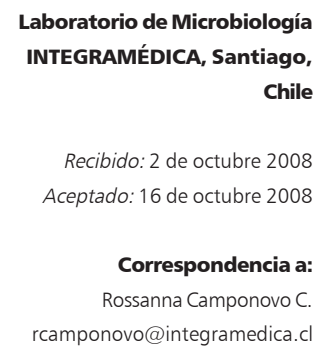

Laboratorio de Microbiología iago, \section{In vitro susceptibility patterns of bacterial species isolated in outpatients of the
Metropolitan Region, Chile, year 2007}

A partial surveillance of bacterial in vitro susceptibility to antibiotics, performed by a outpatient clinic, at Santiago, Chile, during year 2007, has yielded the following results: Staphylococcus aureus (n: 232) 3\% of methicillin (oxacillin) resistance; Streptococcus pyogenes (n: 120) 6\% of macrolides resistance; Haemophilus influenzae nt (n: 60) 12\% of ampicillin and 3\% of chloramphenicol resistance; Neisseria gonorrhoeae (n: 170): $78 \%$ of penicillin, $56 \%$ of tetracyclin and $32 \%$ of ciprofloxacin resistance; Escherichia coli obtained from urine: (adults n: 3.066 , children n: 260) 27-28\% of sulpha-trimethoprim resistance, $15 \%$ (children) $-21 \%$ (adults) of cefadroxil resistance.

Key words: Community, antimicrobial agents, in vitro resistance.

Palabras clave: Comunidad, antimicrobianos, resistencia in vitro.

\section{Nota del Editor:}

Nos ha parecido del mayor interés difundir el siguiente informe de susceptibilidad in vitro extraído de la Tarjeta de Susceptibilidad de un laboratorio para atención de pacientes ambulatorios, el cual tiene distribuidas tomas de muestras en toda el Área Metropolitana de Santiago, pues representa patrones de susceptibilidad de infecciones genuinamente adquiridas en la comunidad. Usualmente se dispone de y publica información emanada de laboratorios hospitalarios; algunos de estos estudios intentan separar pacientes ambulatorios de internados, persistiendo un sesgo de estar representados entre las infecciones ambulatorias, un porcentaje indefinible de infecciones que realmente fueron adquiridas en el hospital.

Durante el año 2007 y 2008 un grupo de microbiólogos representantes de varios laboratorios públicos y privados de Santiago y regiones se ha reunido periódicamente con el fin de estandarizar la manera de informar la susceptibilidad y poder aportar datos nacionales.

$\mathrm{E}$ 1 conocimiento de los patrones de susceptibilidad puede ser usado para orientar la elección de la terapia empírica mientras los resultados del cultivo y evaluación de la susceptibilidad están pendientes. Estos datos no reemplazan a los estudios de susceptibilidad de patógenos individuales.

El siguiente informe entrega resultados de evaluación in vitro por método de difusión con disco (Kirby Bauer) y/o dilución/difusión (epsilometría-E-test ${ }^{\mathbb{R}}$ ) que permite conocer la concentración inhibitoria mínima (CIM). Para cada antimicrobiano y microorganismo se han establecido las categorías de susceptible, intermedio o resistente según halos de inhibición, de acuerdo a criterios internacionales (CLSI-2007).
Se considera susceptible (S) a una cepa si puede ser tratada exitosamente con las dosis recomendadas del antimicrobiano para la especie bacteriana y sitio de infección.

La categoría intermedia (I) incluye cepas cuyas CIM pueden ser alcanzadas en sangre o tejidos con porcentajes de respuesta menor que las cepas susceptibles. El antimicrobiano se podrá usar en sitios donde alcance alta concentración o se pueda utilizar a mayor dosis.

Una cepa es resistente $(\mathrm{R})$ si las concentraciones séricas del antimicrobiano con dosis indicadas para esa patología no inhiben su multiplicación. 
Tabla 1. Bacilos gramnegativos de origen ambulatorio en muestras de orina. Resultados expresados en porcentajes de susceptibilidad (no se considera categoría intermedia, salvo que se especifique). Método: difusión en agar (K \& B)

\begin{tabular}{|c|c|c|c|c|c|}
\hline & $\begin{array}{c}\text { Esherichia coli } \\
\text { (adultos) }\end{array}$ & $\begin{array}{c}\text { Escherichia coli } \\
\text { (niños) }\end{array}$ & $\begin{array}{c}\text { Escherichia coli } \\
\text { BLEE (+) }\end{array}$ & Klebsiella pneumoniae & Proteus mirabilis \\
\hline$N^{\circ}$ de cepas & 3.066 & 250 & 76 & 166 & 162 \\
\hline Ampicilina & 43 & 48 & 0 & 0 & 81 \\
\hline Cefradina/cefadroxilo* & 79 & 85 & 0 & 78 & 93 \\
\hline Cefuroxima & 90 & 96 & 0 & 90 & 94 \\
\hline Cefotaxima/ceftriaxona & 97 & 99 & 0 & 98 & 95 \\
\hline Gentamicina & 96 & 98 & 71 & 99 & 93 \\
\hline Amikacina & 99 & 100 & 79 & 99 & 95 \\
\hline Ciprofloxacina & 85 & 96 & 8 & 98 & 93 \\
\hline Cotrimoxazol & 73 & 72 & 11 & 90 & 85 \\
\hline Nitrofurantoína & 98 & 99 & 84 & 76 & 0 \\
\hline Piperacilina/tazobactam & NT & NT & 87 & NT & NT \\
\hline Ertapenem & NT & NT & 100 & NT & NT \\
\hline Imipenem & NT & NT & 100 & NT & NT \\
\hline Ertapenem & NT & NT & 100 & NT & NT \\
\hline
\end{tabular}

Tabla 2. Staphylococcus aureus de origen ambulatorio. Resultados expresados en porcentajes de susceptibilidad

(no se considera la categoría intermedia). Método: difusión en agar (K \& B)

No cepas: 232

$\%$ de susceptibilidad

$\begin{array}{ll}\text { Oxacilina } & 97\end{array}$

Cotrimoxazol 99

Clindamicina 88

Eritromicina 82

Ciprofloxacina 90

Cloranfenicol $\quad 96$

Tetraciclina 99

$\begin{array}{ll}\text { Vancomicina } & 100\end{array}$

Incluye cepas de piel, expectoración, ótica, líquido peritoneal. No incluye cepas de origen nasal.

Las cepas susceptibles o resistentes a oxacilina (cloxacilina, meticilina) son susceptibles o resistentes también a combinaciones de $\beta$-lactámicos/inhibidores de $\beta$-lactamasa, cefalosporinas y carbapenem.
Tabla 3. Streptococcus de origen ambulatorio. Resultados expresados en porcentajes de susceptibilidad (no se considera la categoría intermedia). Método: difusión en agar (K \& B) y epsilometría (E-test $\left.{ }^{\circledR}\right)$

\begin{tabular}{lcccc} 
& $\begin{array}{c}\text { Streptococcus } \\
\text { pyogenes } \\
\text { (grupo A) }\end{array}$ & $\begin{array}{c}\text { Streptococcus } \\
\text { grupos C y G }\end{array}$ & $\begin{array}{c}\text { Streptococcus } \\
\text { agalactiae } \\
\text { (grupo B) }\end{array}$ & $\begin{array}{c}\text { Streptococcus } \\
\text { pneumoniae }\end{array}$ \\
\hline No de cepas & 120 & 32 & 471 & 38 \\
\hline Penicilina & 100 & 100 & 100 & 79 \\
\hline Amoxicilina & NT & NT & NT & 100 \\
\hline Eritromicina & 94 & 84 & 84 & 63 \\
\hline Clindamicina & 95 & 84 & 85 & 95 \\
\hline Cotrimoxazol & NT & NT & NT & 84 \\
\hline Cloranfenicol & NT & NT & NT & 100 \\
\hline Levofloxacina & NT & NT & NT & 100 \\
\hline
\end{tabular}

Las cepas de Streptococcus pneumoniae corresponden a aislados en sangre, expectoración, secreción ótica y vaginal. No incluye cepas de origen nasal.

Streptococcus grupos A, B, C y G susceptibles a penicilina, también lo son a amoxicilina y cefalosporinas.

Las cepas susceptibles o resistentes a eritromicina también son susceptibles o resistentes a claritromicina y azitromicina.

NT: no testeado 


\begin{tabular}{|c|c|}
\hline No cepas: 170 & $\%$ de susceptibilidad \\
\hline Penicilina & 22 \\
\hline Tetraciclina & 44 \\
\hline Ciprofloxacina & 68 \\
\hline Cefotaxima/Ceftriaxona & 100 \\
\hline
\end{tabular}

\section{Resumen}

Una vigilancia parcial de la susceptibilidad bacteriana a antimicrobianos en la comunidad de Santiago, Chile, en el año 2007, efectuada por un centro de atención ambulatoria, ha dado las siguiente frecuencia de resistencia in vitro: Staphylococcus aureus (n: 232)

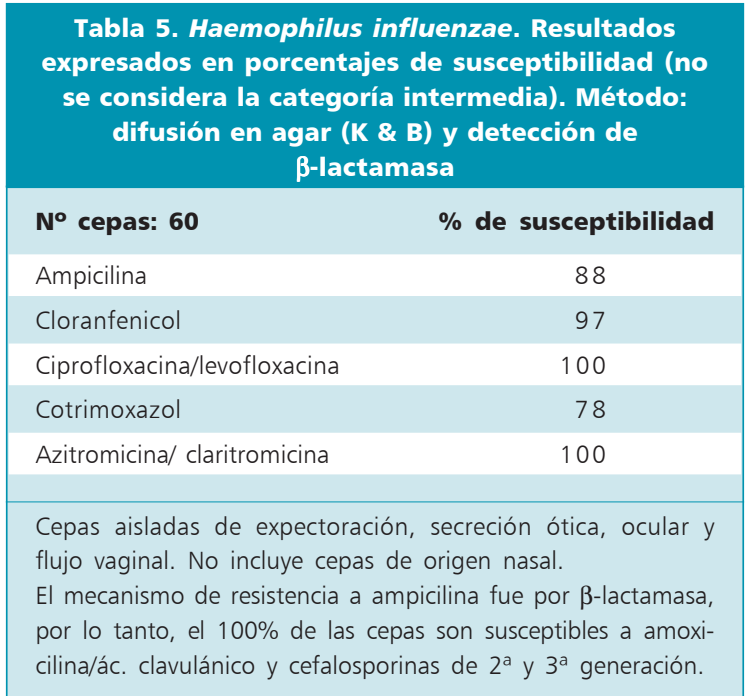

3\% a meticilina (cloxacilina); Streptococcus pyogenes (n: 120) 6\% a macrólidos; Haemophilus influenzae nt (n: 60) $12 \%$ a ampicilina y $3 \%$ a cloranfenicol; Neisseria gonorrhoeae (n: 170): 78\% a penicilina, 56\% a tetraciclina y $32 \%$ a ciprofloxacina; Escherichia coli uropatógenas: (adultos n: 3.066, niños n: 260) 27-28\% a cotrimoxazol, $15 \%$ (niños) $-21 \%$ (adultos) a cefadroxilo. 